\title{
AS EXPRESSÕES DA QUESTÃO SOCIAL NA SAÚDE MENTAL: Uma análise nos 4 CAPSs II de Teresina - PI
}

\author{
Sofia Laurentino Barbosa Pereira \\ Universidade Federal do Piauí - UFPI - Brasil \\ Simone De Jesus Guimarães \\ Universidade Federal do Piauí - UFPI - Brasil
}

\section{Resumo}

Este artigo possui como objetivo analisar as expressões da questão social e as principais demandas postas aos assistentes sociais em seu trabalho na saúde mental, utilizando como cenários os 4 Centros de Atenção Psicossocial (CAPSs) II da cidade de Teresina - PI. Trata-se de uma pesquisa de campo, em que foram entrevistados 8 assistentes sociais e analisadas as suas falas com base no método dialético de Marx (1989), numa busca pela reprodução ideal do movimento do real. Assim, buscou-se reconstruir o processo do objeto historicamente dado, para além de sua aparência fenomênica, resultante de uma elaboração teórica, tendo como base a literatura sobre o tema, com ênfase em Iamamoto (2001; 2008), Rosa (2008), além da utilização de dados e documentos do Ministério da Saúde (BRASIL, 2004; 2012). Constatouse que grande parte dos usuários desses serviços são pessoas que, além de sofrerem com transtorno mental, sofrem também com a pobreza e suas consequências, o que vai demandar ao assistente social uma atenção que vai além da assistência em saúde mental, transcorrendo as diversas expressões da questão social.

Palavras chaves: Serviço Social. Saúde Mental. Questão Social.

\section{Introdução}

Este artigo, elaborado com base em dados coletados para o trabalho de dissertação de mestrado da autora, possui como objetivo analisar as expressões da questão social e as principais demandas postas aos assistentes sociais em seu trabalho na saúde mental, utilizando como cenários os 4 Centros de Atenção Psicossocial (CAPSs) II da cidade de Teresina - PI: CAPS II Norte, o CAPS II Leste, o CAPS II Sul e o CAPS II Sudeste.

Nesses cenários tem-se um total de 14 assistentes sociais, dos quais 8 foram selecionados para participarem dessa investigação enquanto Sujeitos, onde foram questionadas acerca do seu trabalho através de entrevistas semiestruturadas. Destarte, faz-se necessário destacar a relevância da amostra coletada, que se consolida em 57\% da amostra total de profissionais de Serviço Social inseridos nas instituições pesquisadas. Os mesmos foram apresentados ao Termo de Consentimento Livre e Esclarecido (TCLE), elaborado de acordo 
com a Resolução 466/12 do Conselho Nacional de Saúde (CNS) e, após concordarem participar da investigação, foram submetidos a entrevistas elaboradas a partir de um roteiro semiestruturado.

Após a coleta dos dados, as falas dos sujeitos foram analisadas tomando por base o método dialético de Marx (1989), onde se buscou ir além da aparência fenomênica, imediata e empírica da realidade e das falas dos sujeitos, para apreender sua essência, sua dinâmica e suas contradições, numa busca pela reprodução ideal do movimento do real.

Ressalta-se que, na perspectiva marxiana, o método está diretamente relacionado à posição que o pesquisador se coloca perante o objeto, buscando extrair dele suas múltiplas determinações. Assim, segundo Marx (1989), não se constrói um objeto e, sim, se reconstrói o processo do objeto historicamente dado. A resultante da elaboração teórica, o produto teórico por excelência, é uma reprodução ideal de um processo real. Nesse sentido, o que a teoria nos ilumina para refletir, entender e explicar, é a totalidade concreta da realidade.

Destarte, para a compreensão da realidade dos CAPSs II de Teresina enquanto totalidade concreta se fez necessário construir o arcabouço teórico acerca da temática, isto é, proceder a uma ampla e detalhada investigação acerca das ideias norteadoras do tema escolhido. Assim, após a coleta dos dados os mesmos foram analisados à luz do referencial teórico, que tomou por base os principais autores: Iamamoto (2001; 2008) e Netto (2011) na discussão do Serviço Social e da Questão Social; Machado (2013) e Rosa (2008) para análise do Serviço Social no cenário da Saúde Mental; além da utilização de relatórios, dados e documentos do Ministério da Saúde (BRASIL, 2004; 2012).

\section{Serviço social, questão social e saúde mental}

Pensar o Serviço Social enquanto trabalho implica compreender a profissão essencialmente vinculada a interesses das classes contraditórias que fundamentam a sociedade capitalista. Assim, ela se afirma como um tipo de especialização do trabalho coletivo, ao ser expressão de necessidades sociais derivadas da prática histórica das classes sociais no enfrentamento da questão social e suas expressões.

A questão social não é, aqui, focada exclusivamente como desigualdade social entre pobres e ricos, mas como desigualdade em sua gênese, em um contexto em que acumulação de capital não rima com equidade; desigualdades indissociáveis da concentração de renda, de propriedade e poder, que são o verso da violência, da pauperização e das formas de discriminação e exclusão social (IAMAMOTO, 2008). 
Assim, ao se falar sobre questão social não se pode reduzi-la ao reconhecimento da pobreza e da miséria, mas sim, ao reconhecimento do impasse existente nas sociedades modernas a fim de desvelar a contradição permanente entre a lógica do mercado e a dinâmica societária.

Netto (2011) reafirma esse posicionamento, alegando que a questão social está profundamente relacionada com a consolidação do modo de produção capitalista, que tem como essência a acumulação de capital oriunda da exploração da mão-de-obra do trabalhador, desprovido dos meios de produção, gerando o conflito entre explorados e exploradores. A pressão dos trabalhadores faz o contraponto - as resistências. A classe trabalhadora organizada, pressionando, obriga o Estado a assumir as demandas dessa classe como questão social.

Ainda nessa perspectiva, Iamamoto (2001, p.16) ressalta que a questão social:

[...] diz respeito ao conjunto das expressões das desigualdades sociais engendradas na sociedade capitalista madura, impensáveis sem a intermediação do Estado. Tem sua gênese no caráter coletivo da produção, contraposto a apropriação privada da própria atividade humana - o trabalho -, das condições necessárias a sua realização, assim, como de seus frutos.

Assim, compreende-se que advento da questão social está relacionado diretamente ao processo de formação de um mercado de trabalho nos moldes do modo de produção capitalista.

Destarte, são as necessidades impostas pela questão social que, em suas variadas expressões, dão legitimidade para a atuação do assistente social diante da realidade.

Os assistentes sociais trabalham com a questão social nas suas mais variadas
expressões quotidianas [...]. Questão social que, sendo desigualdade, também é
rebeldia, por envolver sujeitos que vivenciam as desigualdades e a ela resistem e se
opõem. É nesta tensão entre produção da desigualdade e produção da rebeldia e da
resistência que trabalham os assistentes sociais, situados nesse terreno movido por
interesses sociais distintos, aos quais não é possível abstrair ou deles fugir, porque
tecem a vida em sociedade (IAMAMOTO, 2008, p.28).

Assim, considera-se que o objeto ou matéria-prima do trabalho do Serviço Social se encontra no âmbito da questão social, pois é ela que provoca a necessidade de intervenção desse profissional em suas múltiplas determinações, tal como vivenciadas pelos indivíduos sociais em suas relações cotidianas. Essas expressões da questão social são abordadas por esse profissional por meio de inúmeros recortes, pois assumem características específicas, de acordo com a realidade em que se insere.

No espaço sócio-ocupacional da saúde mental, o Serviço Social atua sobre as expressões da questão social que se manifestam a partir da exclusão da pessoa com transtorno mental do sistema produtivo e do convívio social pelo estigma social que 
passou a fazer parte da sua identidade, haja vista ser considerado, historicamente, pela sociedade, como uma pessoa perigosa e incapaz, portanto, que deve ser excluída do convívio social. Além do próprio histórico de exclusão social ao qual foi submetida à pessoa com transtorno mental, que se traduz no imaginário social da sociedade na expressão comum de que "lugar de louco é no hospício", e do estigma e preconceito que passou a rondar esse segmento social e seus familiares.

Portanto, o assistente social na área da saúde mental vem trabalhar com os desafios postos pelas expressões da questão social que permeiam a vida da pessoa com transtorno mental e sua família.

\section{As expressões da questão presentes nos CAPSS de Teresina - PI}

A referida investigação ocorreu nos cenários dos 4 Centros de Atenção Psicossocial II de Teresina, capital do Piauí, onde foram entrevistadas 8 assistentes sociais que trabalham nessas instituições.

Antes de adentrar na análise das falas dos Sujeitos de pesquisa, onde se buscou desvelar as expressões da questão social presentes nessas instituições, faz-se necessário compreender mais sobre esses cenários e Sujeitos de pesquisa.

\section{Os Sujeitos e os cenários da pesquisa: os assistentes sociais que trabalham nos 4 CAPSs II de Teresina - PI}

Os Centros de Atenção Psicossocial (CAPSs), regulamentados em 19 de fevereiro de 2002 pela Portaria de $n^{\circ}$ 336, do Ministério da Saúde, são instituições destinadas a acolher pessoas com transtornos mentais severos e persistentes, estimulando sua integração social e familiar, apoiando-os em suas iniciativas de busca da autonomia, realizando acompanhamento clínico e a reinserção social dos usuários pelo acesso ao trabalho, lazer, exercício dos direitos civis e fortalecimento dos laços familiares e comunitários (BRASIL, 2004). Os CAPSs são considerados a principal estratégia da Reforma Psiquiátrica no Brasil, na medida em que visam uma nova forma de tratamento e atenção à pessoa com transtorno mental que esteve, historicamente, circunscrita pela segregação social, enclausuramento e exclusão, característicos do modelo manicomial e hospitalocêntrico.

A décima primeira edição do "Saúde Mental em Dados", um levantamento do Ministério da Saúde sobre a Rede de Atenção Psicossocial no Brasil (BRASIL, 2012), traz uma 
série histórica mostrando a expansão dos Centros de Atenção Psicossocial (CAPSs) do ano de 1998 a 2012, apontando o significativo aumento desses serviços nesse intervalo, com os números expandindo de 148 para 1.803 CAPSs em todo o Brasil.

A cobertura desses serviços, ao final de 2002, quando existiam 424 CAPSs, era de $21 \%$, em âmbito nacional. Em julho de 2011, tem-se o aumento para 1.650 Centros de Atenção Psicossocial, cobrindo 68\% das regiões do país. Em junho de 2012, esse número já cresce para 1.803, desses, 848 são CAPSs do tipo I, 434 do tipo II, 66 do tipo III, 158 CAPSs infantil, 281 CAPSs voltados para pessoas dependentes de álcool e outras drogas e 12 CAPSs do tipo III, mas com o público voltado também para dependentes de álcool e outras drogas.

O informativo faz um destaque ao desempenho da região Nordeste, onde houve um expressivo crescimento de CAPS, atingindo uma cobertura assistencial considerada muito boa. De acordo com o Ministério da Saúde (BRASIL, 2012), observa-se que o adensamento da cobertura desta região supera o de outras regiões do país.

No Piauí, ocorreu um aumento de 0,3 CAPS/100.000 habitantes em 2002, cobertura considerada pelo Ministério da Saúde como insuficiente e crítica, para 0,91 em 2012, totalizando 43 Centros de Atenção Psicossocial no Estado, nesse período, passando a ser considerado com uma cobertura muito boa, segundo os indicadores. Desse total, 30 são CAPSs do tipo I, 7 do tipo II, 1 do tipo III, 1 voltado para o público jovem e infantil, até os 18 anos e 4 destinados a usuários de álcool e outras drogas (BRASIL, 2012).

De acordo com esse levantamento o Piauí aparece, em 2012, como o oitavo Estado brasileiro com melhor cobertura de CAPS, ao sair da média de 0,03 em 2002, para 0,91 em 2012. Os demais Estados que aparecem com desempenho superior são: Rio Grande do Norte $(1,92)$, Paraíba $(1,39)$, Sergipe $(1,16)$, Rio Grande do Sul $(1,12)$, Ceará $(0,98)$, Alagoas $(0,95)$ e Santa Catarina (0,94). Ressalta-se que dos oito Estados do país considerados com maior cobertura assistencial de serviços de CAPS, seis estão localizados no Nordeste.

Após uma pesquisa mais recente no site de Cadastro Nacional de Estabelecimentos de Saúde (CNES), de dados oficiais do Ministério da Saúde (BRASIL, 2015), observou-se que o Piauí atualmente consta com uma totalidade de 61 Centros de Atenção Psicossocial - portanto, nota-se que houve um aumento de 18 CAPSs do ano de 2012 a 2015. Desse total, 7 se localizam na cidade de Teresina, capital do estado. São eles: 1 Centro de Atenção Psicossocial Infantil (CAPSi), 1 Centro de Atenção Psicossocial para dependentes de álcool e outras drogas (CAPSad), 1 Centro de Atenção Psicossocial com funcionamento 24 horas (CAPS III) e 4 Centros de Atenção Psicossocial do tipo II (CAPS II). 
Esses 7 CAPSs, mesmo tendo em comum o objetivo de tirar o foco dos hospitais psiquiátricos e substituí-los por outros serviços abertos e comunitários, que atendam às necessidades sociais do indivíduo com transtorno mental, são diferenciados entre si. O CAPSi tem como público crianças e adolescentes com transtorno mental, com até 18 anos de idade. $\mathrm{O}$ CAPSad é voltado para usuários de álcool e outras drogas. O CAPS II é para atendimento de pessoas com transtornos mentais severos e persistentes, maiores de 18 anos, atendendo durante a semana, nos turnos manhã e tarde. Essa modalidade de serviço é voltada para os municípios com população entre 70.000 e 200.000 habitantes. Já o CAPS III é uma modalidade de serviço oferecida 24 horas, diariamente, incluindo feriados e finais de semana, podendo oferecer um acolhimento noturno para aqueles indivíduos que estão em crise, evitando a internação em hospitais psiquiátricos. Para essa pesquisa, os cenários utilizados foram os 4 CAPSs II da cidade, são eles: CAPS II Norte, CAPS II Leste, CAPS II Sul e CAPS II Sudeste.

O CAPS II Norte, fundado em 28 de novembro de 2005, conta com um total de 23 profissionais de nível superior, sendo eles: 04 assistentes sociais, 02 educadores físicos, 04 enfermeiros, 02 nutricionistas, 05 médicos psiquiatras, 04 psicólogos e 02 terapeutas ocupacionais. Até o final de 2012, computava-se um total de mil e quatrocentos (1.400) usuários inscritos no serviço. Dentre esses, quinhentos e sessenta e oito (568) frequentam mensalmente a instituição.

O CAPS II Leste, criado em 25 de novembro de 2005, conta com uma equipe profissional de 20 técnicos de nível superior, sendo eles: 04 assistentes sociais, 02 educadores físicos, 04 enfermeiros, 02 nutricionistas, 03 médicos psiquiatras, 03 psicólogos e 02 terapeutas ocupacionais. No ano de 2014 o serviço constava com um total de mil trezentos e sessenta e nove (1.369) usuários inscritos. Dentre esses, quatrocentos e cinquenta (450) frequentam mensalmente a instituição.

O CAPSs II Sul da cidade de Teresina foi fundado em 21 de dezembro de 2009 e tem uma equipe formada por 17 profissionais técnicos de nível superior, sendo eles: 03 assistentes sociais, 02 educadores físicos, 03 enfermeiros, 02 nutricionistas, 03 médicos psiquiatras, 02 psicólogos e 02 terapeutas ocupacionais. Até o ano de 2013, o CAPS II Sul contava com o total de quinhentos e setenta e um (571) usuários cadastrados no serviço, desse total, duzentos e sessenta e seis (266) são ativos, ou seja, frequentam mensalmente a instituição.

O CAPS II Sudeste foi inaugurado em 18 de fevereiro de 2010 e tem uma equipe composta por 17 profissionais técnicos de nível superior, sendo eles: 03 assistentes sociais, 02 educadores físicos, 02 enfermeiros, 02 nutricionistas, 03 médicos psiquiatras, 02 psicólogos e 02 terapeutas ocupacionais. No ano de 2014 a instituição conta com o total de mil e vinte e sete 
(1.027) prontuários que identificam os usuários cadastrados no serviço, desse total, quinhentos e sessenta e um (561) são ativos, ou seja, frequentam mensalmente o CAPS.

Em relação aos profissionais que atuam nas instituições, faz-se necessário destacar que de acordo com a Portaria Ministerial n ${ }^{\circ} 336$, de 2002, a equipe técnica mínima para atuação no CAPS II, para o atendimento de 30 pacientes por turno, deve ser composta por: 01 médico psiquiatra; 01 enfermeiro com formação em saúde mental; 04 profissionais de nível superior, devendo ser, entre os escolhidos, psicólogo, assistente social, enfermeiro, terapeuta ocupacional, pedagogo ou outro profissional necessário ao projeto terapêutico; 06 profissionais de nível médio.

Assim, a equipe de nível superior dos CAPSs II de Teresina totaliza 77 profissionais nos 04 CAPSs e, desses: 14 são assistentes sociais; 08 educadores físicos, 13 enfermeiros, 08 nutricionistas, 14 médicos psiquiatras, 12 psicólogos e 08 terapeutas ocupacionais. Foi possível constatar que a equipe é formada por uma quantidade maior que o mínimo exigido pelo ato administrativo normativo referente aos Centros de Atenção Psicossocial.

Especificamente, em relação ao Serviço Social, foi possível identificar que os CAPSs II da cidade contam com 14 assistentes sociais no total, sendo que os Centros de Atenção Psicossocial das zonas Leste e Norte constam com 04 profissionais de Serviço Social em cada instituição, e os CAPSs das zonas Sul e Sudeste com 03 em cada, com o detalhe que o CAPS Sul conta com uma assistente social que trabalha nos dois turnos, por isso a instituição contabiliza 03 assistentes sociais, em vez de 02. Destarte, na realidade investigada, é importante ressaltar que todos os Centros de Atenção Psicossocial da cidade apresentam assistentes sociais compondo a equipe, sendo que os CAPSs que inauguraram a mais tempo - que são os CAPSs II Leste e Norte, ambos implantados no ano de 2005 - somam uma quantidade maior de assistentes sociais do que o mínimo exigido pela Portaria Ministerial no 336, de 2002.

Para essa pesquisa, foram entrevistadas 08 assistentes sociais, dos 14 profissionais de Serviço Social da totalidade dos 04 CAPSs II de Teresina, sendo 02 de cada instituição, 01 de cada turno. Destarte, faz-se necessário destacar a relevância da amostra coletada, que se consolida em 57\% da amostra total de profissionais de Serviço Social inseridos nas instituições pesquisadas.

\section{Análise das expressões da questão social presentes nos CAPSs II de Teresina e as principais demandas para os assistentes sociais}


Compreendendo a questão social como objeto do trabalho do Serviço Social, as assistentes sociais dos CAPSs de Teresina foram questionadas acerca das expressões da questão social que estão presentes no cotidiano seu trabalho nessas instituições e a questão da vulnerabilidade social, tanto do usuário quanto de sua família, foi destaque em diversos momentos, como se constata no discurso do Sujeito ${ }^{1}$ a seguir:

Nós podemos dizer que majoritariamente o usuário que nos busca, embora saibamos
que o CAPS está aberto a todo indivíduo que dele necessitar, majoritariamente, quem
nos busca são as pessoas que estão nos extratos sociais mais baixos. Quem, por
exemplo, pode disponibilizar de um plano de saúde ou um atendimento pela rede
privada, vai optar pela rede privada. Então, o que significa? Que nós vamos ter aqui
como sujeito da nossa intervenção, majoritariamente, aquele sujeito que também tem
seu conjunto de vulnerabilidades sociais como, por exemplo, a pobreza, a exclusão do
mercado de trabalho, a precarização do mundo de trabalho, forma como se inscreve
esse mercado de trabalho, muitas vezes através da informalidade [...] Então, podemos
dizer que é um sujeito que tem um feixe de necessidades, um conjunto de
vulnerabilidades e, portanto, é necessário que tenhamos um olhar pra ele, de maneira
a poder analisar que demandas são essas e poder intervir de modo a tentar reduzir
(SUJEITO 4).

$\mathrm{Na}$ fala acima, é possível averiguar que o Sujeito entrevistado 4 aponta como o principal segmento de usuários do serviço do CAPS, aquele indivíduo que sofre de vulnerabilidade social, o que envolve uma série de expressões da questão social, como a pobreza, que envolve também a exclusão do mercado de trabalho, ou a informalidade, a ausência de moradia digna e até mesmo a falta de alimentação. Nessa mesma direção, reforça a entrevistada abaixo:

Tem usuário aqui que ele vem porque ele não tem o que comer em casa, é verdade, ele não tem comida. Comida também é saúde, né. Aí entra o conflito com a nutrição, entra o embate com a nutrição, a correlação de força com a nutrição. Porque a nutrição, pra ela, eu tenho que ter número $\mathrm{X}$ de refeições pra número $\mathrm{X}$ de usuários que realmente estão no serviço. Mas não explica pra ela, às vezes ela não aceita, o usuário que não é pra estar aqui, que vem e se você for escutar, ele não tem comida lá meiodia. Então, ele vem, come e vai embora. Isso deixa alguns técnicos horrorizados: "Ah, mas ele só vem pra comer”. Ele só vem pra comer porque ele não tem. Entendeu? Ele sabe que no serviço tem. Então, a expressão da questão social também tá aí: na comida que ele não tem (SUJEITO 1).

A fala das entrevistadas 1 e 4 acima, reflete o pensamento de Rosa e Campos (2013, p.314), ao afirmarem que no campo da saúde mental, historicamente, houve um predomínio dos serviços se conformarem focados nos segmentos de baixa renda, o que tem fortes reflexos e marcos na atualidade. Para as autoras, existe uma tendência da assistência em saúde mental ter uma clivagem preponderante de classe social, ou seja, ser destinada aos segmentos pobres e trabalhadores empobrecidos da população. São esses usuários, em situações de vulnerabilidade social, econômica, política e cultural, que vão demandar

\footnotetext{
${ }^{1}$ Os assistentes sociais participantes da pesquisa serão aqui nomeados por Sujeitos e numerados de 1 a 8.
} 
o trabalho do assistente social nas mais variadas expressões da questão social - no caso, essas expressões da questão social vão demandar a intervenção desse profissional nos Centros de Atenção Psicossocial. O ponto de vista das autoras pode ser observado no trecho a seguir:

As desigualdades sociais na saúde mental materializam-se a partir de diferentes
formas de acesso a cuidados, determinadas pela origem de classe da pessoa com
transtorno mental. Em parte da literatura europeia e latino-americana, o
reconhecimento da predominância do modelo hospitalocêntrico na assistência
psiquiátrica pública é acompanhado pelo seu endereçamento específico de classe
social como uma resposta do Estado à questão social posta por segmentos da classe
trabalhadora, os loucos pobres (ROSA; CAMPOS, 2013, p.314).

A perspectiva das autoras pode ser vislumbrada em outro momento, quando Sujeito 1 reforça, novamente, como o CAPS é visto como um “[...]serviço para pobre e para louco", o que leva, muitas vezes, aos próprios usuários terem preconceito com o serviço. A entrevistada afirma a urgência de se desmistificar a concepção que a maioria das pessoas tem de que o serviço público é ineficiente, e de que o CAPS é um serviço voltado para pessoas "pobres, loucas e perigosas” (SUJEITO 1). Pois só assim novos segmentos populacionais poderão chegar até a instituição.

A entrevistada 3 reafirma essa questão do preconceito no trecho a seguir:

Existe bastante ainda essa questão do preconceito, é algo ainda muito presente nas comunidades. "Ah, olha ali um paciente do CAPS!” [...] Aqui a gente não usa jaleco, a gente não usa roupa branca, uma forma da gente "desestigmatizar" um pouco essa visão. E às vezes a família identifica: "Ah, ali naquela casa mora uma pessoa [...] do CAPS!” Então, fica esse estigma da doença mental, é muito presente (SUJEITO 3).

A partir da fala do Sujeito 3 se pode conceber que as desigualdades sociais presentes no campo da saúde mental se materializam a partir de diferentes formas de acesso aos serviços de cuidados, determinados pela origem de classe da pessoa com transtorno mental. Dessa forma, apesar de os serviços de saúde mental serem públicos e universais, ou seja, todo e qualquer indivíduo de qualquer classe social pode ter acesso a ele - se estiver de acordo com o perfil do serviço, como nos Centros de Atenção Psicossocial, que atendem as pessoas com transtornos mentais graves e persistentes - entretanto, existe um reconhecimento da predominância de usuários desses serviços serem vinculados a uma classe social específica, a classe trabalhadora, consequentemente, mais vulnerável economicamente falando.

No depoimento do Sujeito 8, a seguir, é possível vislumbrar, novamente, o usuário do CAPS como uma pessoa que advém de uma classe social mais baixa, permeada pela questão da pobreza: 
Quem é o nosso usuário aqui? É aquela pessoa que tem a classe econômica bem baixa, são pessoas que estão na linha da pobreza ou abaixo dela, com raríssimas exceções. Inclusive, as exceções, eu tenho observado que são pessoas que vêm, praticamente, só para consulta. As pessoas que vêm para participar das atividades terapêuticas, do dia a dia, da rotina do serviço, geralmente são as pessoas que têm a condição econômica bem baixa mesmo, da linha da pobreza pra baixo (SUJEITO 8).

Verifica-se, assim, que grande parte das pessoas que utilizam o serviço dos CAPSs II de Teresina são pessoas que, além de sofrerem com transtorno mental, sofrem também com a pobreza e suas consequências. Reforça-se, portanto, a concepção apontada por Rosa e Campos (2013, p.315), anteriormente, de que os serviços públicos se voltam para atender pessoas de uma classe social específica.

Segundo essas autoras, tais características acompanharam historicamente a assistência psiquiátrica - tanto nacional quanto internacionalmente - diferenciada conforme a origem de classe dos usuários dos serviços. Para os pobres, os serviços públicos; para os segmentos mais aquinhoados economicamente, os serviços da medicina privada, mais elitizada, geralmente de melhor qualidade e preservadores da autonomia da pessoa com transtorno mental e, consequentemente, de seus direitos.

Essa perspectiva pode ser percebida atualmente em outros serviços no Brasil, que não apenas os voltados para a pessoa com transtorno mental. No caso, na saúde e da educação, por exemplo, apesar de serem serviços públicos e que deveriam ser oferecidos universalmente a todos os cidadãos brasileiros, verifica-se que aqueles que podem pagar vão recorrer ao setor privado, que geralmente oferece os mesmos serviços, mas com uma qualidade melhor. Esse fator reforça a noção de desvalorização do público em detrimento do privado, decorrente da não priorização e/ou valorização das políticas públicas e sociais por parte do poder estatal. Desta forma, as políticas públicas e sociais não são o carro chefe de incentivo do Estado no sentido de proporcionar serviços públicos de qualidade a todos, deixando para se utilizar desses apenas aqueles cuja classe social é mais vulnerável econômica e socialmente.

Tais circunstâncias se fortalecem devido ao ideário neoliberal que justamente incentiva o Estado a investir cada vez menos em serviços públicos e sociais, passando a ocorrer uma verdadeira desresponsabilização estatal em relação ao social, deixando para o setor privado e para a própria sociedade a tarefa da proteção social.

Assim, percebeu-se que por mais que o usuário do Centro de Atenção Psicossocial seja a pessoa que sofre de intenso sofrimento psíquico, com transtorno mental grave e persistente, esses indivíduos são vistos pelo Serviço Social em uma concepção mais ampliada, no sentido de apreender as expressões da questão social que esse sujeito traz consigo, mas que muitas vezes não podem ser percebidas em sua imediaticidade. Isso reforça o pensamento de Rosa 
(2008, p.115) ao afirmar que o assistente social, nesses novos serviços de saúde mental, no caso do CAPS, atua diretamente sobre as expressões da questão social e elas se manifestam, principalmente, no preconceito que ronda esse indivíduo com transtorno mental.

Essa pessoa, além do estigma social que o circunscreve, passa a ser considerado também como incapaz para o sistema produtivo e para a vida no trabalho, levando, portanto, a acentuar a questão da pobreza e da vulnerabilidade social para esse segmento.

Sobre isso, o depoimento do Sujeito 5 reforça:

\begin{abstract}
Por mais que seja um serviço de saúde mental, a gente tem demandas de todas as áreas que você imaginar, então, nós temos usuários de extrema vulnerabilidade social, nós temos questão de famílias extremamente sobrecarregadas, famílias que tentam abandonar o usuário [...] Olha, nós temos usuários que não têm o que comer, que não têm onde ficar, temos usuários que têm filhos e que os filhos foram retirados por conta da condição do usuário, então, são demandas bem completa, nós temos demanda de cárcere privado, nós temos demandas de assistência, até a demanda mais simples, de um passe livre, de um bolsa família a demandas mais complexas de usuários que foram abandonados pelo familiar, então, várias expressões realmente da questão social no nosso dia a dia, que às vezes eles nem imaginam que eles possam se depararem com elas no CAPS (SUJEITO 5).
\end{abstract}

Assim, pode-se apreender que as assistentes sociais entrevistadas ressaltaram, principalmente enquanto expressão da questão social no cotidiano institucional, as demandas mais materiais postas pelos usuários e seus familiares, principalmente no que se refere à falta de renda.

Trindade (2012, p.78) ressalta que é preciso ter cuidado com as demandas impostas pelo agravamento das expressões da questão social, principalmente na questão da pobreza, pois essa tem como repercussões a prevalência de requisições ao assistente social, que esse limite o seu trabalho a ações paliativas, de cunho individual, assistencialista e emergencial. Portanto, a autora ressalta que diante dessa conjuntura o assistente social é desafiado a criar estratégias que possibilitem a ampliação dos direitos sociais, ainda que em condições restritas.

A questão da pobreza, vinculada à baixa renda - ou mesmo falta de renda -, tem relação direta com o desemprego que circunscreve historicamente a pessoa com transtorno mental, que ainda é vista com preconceito e por isso tem dificuldade de se inserir no mercado de trabalho, como se percebe nos depoimentos a seguir:

Questão da pobreza, a maioria dos nossos usuários são pessoas de baixa renda. A questão do preconceito ao doente mental ainda, a dificuldade da inserção no mercado de trabalho, porque isso junto ao preconceito é outra barreira que precisamos derrubar e até mesmo ainda no preconceito a questão dos encaminhamentos, cursos profissionalizantes pra essas coisas que são de suma importância (SUJEITO 6). 
As expressões são essas: desemprego, falta de moradia, saúde, educação é uma questão muito séria, lazer. Então, as mais diversas. Só que a mais forte aqui no Serviço Social, que eu observo, é o desemprego, que eles sabem que historicamente eles foram e são ainda muito discriminados, o acesso ao mercado de trabalho é praticamente zero pro paciente de saúde mental (SUJEITO 2).

Entende-se que as falas dos Sujeitos convergem em vários sentidos quando advertem sobre a pobreza como uma expressão da questão social presente no cotidiano dos 4 CAPSs II de Teresina.

Entretanto, é necessário ressaltar que pobreza, desemprego, estigma e preconceito, apesar de terem relação e, muitas vezes, terem implicações uns nos outros, têm suas diferenças e especificidades. A pobreza, que surge com frequência no discurso das entrevistadas como expressão da questão social, refere-se principalmente à falta de recursos materiais e financeiros, o que vincula esse usuário com transtorno mental e sua família a uma classe social mais vulnerável economicamente. Essa questão tem relação com o desemprego, na medida em que este é um dos principais geradores dessa pobreza, mas é expressão de uma situação maior, que no caso da pessoa com transtorno mental tem também relação com o estigma e preconceito que permeia aquele sujeito, historicamente considerado louco, perigoso e incapaz para ingressar no mercado de trabalho. Esses fatores têm repercussão no núcleo familiar do usuário, que já se encontra em uma situação de limitações e sobrecarga familiar, devido ao cuidado ao ente com transtorno mental.

Sobre as limitações que sofre a família provedora de cuidados à pessoa com transtorno mental, Rosa (2008, p.171) ressalta que essa geralmente conta apenas com uma pessoa responsável pelo cuidado, o que aumenta a sobrecarga sobre essa e limita sua disponibilidade de se inserir no mercado de trabalho. "O familiar cuidador que trabalha fora sofre com a necessidade de divisão entre os tempos de gerar renda e prover cuidado, arriscando-se ao subemprego ou até mesmo ao desemprego".

Sobre as expressões da questão social que surgem nos serviços de saúde mental, Machado (2013, p.112) as caracteriza em duas: material e cultural. Material por que “[...] a maioria dos usuários dos serviços públicos de saúde mental historicamente foi, e continua a ser composta por pessoas em situação de pobreza e miséria, com rupturas no mercado de trabalho". Cultural, pois permanece o estigma e preconceito que ronda a pessoa com transtorno mental, considerada perigosa e incapaz.

Assim, ao discorrerem sobre as expressões da questão social, os depoimentos dos Sujeitos da pesquisa sempre permeavam a questão da pobreza, consequência muitas vezes do 
desemprego, tanto do usuário como dos seus familiares. Pois o fato de o familiar ser também, no global, o cuidador da pessoa com transtorno mental, também leva a dificuldade do familiar se manter em uma relação de emprego, na medida em que muito do seu tempo é gasto no cuidado a seu ente com transtorno mental, como ressalta o Sujeito 7:

O fato deles não trabalharem, ou não poderem trabalhar, o que às vezes deixa que algum outro membro da família também não possa trabalhar, então isso já prejudica bastante a situação da verba mesmo da família e também assim exclusão né, a gente percebe muito tanto da população, da comunidade quanto da própria família (SUJEITO 7).

Averiguou-se que as expressões da questão social citadas pelas assistentes sociais permeiam os dois aspectos levantados por Machado (2013, p. 116): materialmente, principalmente no que se refere à baixa renda e culturalmente, pelo preconceito da sociedade e, às vezes, dos próprios usuários em relação a eles mesmos e ao serviço, como foi ressaltado por uma assistente social no momento da entrevista.

Outra expressão da questão social que permeia o cotidiano do CAPS é a baixa escolaridade dos usuários, que também está aliada à vulnerabilidade social, à pobreza e ao desemprego, como reflete a entrevistada abaixo:

\footnotetext{
Aqui no CAPS, se você olha de relance [...] a maioria das pessoas que estão aqui são pessoas que têm uma escolaridade muito baixa ou quase nenhuma. Não dizendo que aqui não têm pessoas com escolaridade alta. Têm, têm estudantes universitários. Aqui você encontra pessoas, na sua grande maioria [...] eles não têm uma renda. [...] Alguns, quando têm, é o BPC. Mas nem todos, porque eles estão fora das condicionalidades. Mas têm alguns que têm, outros não têm renda nenhuma, e aí eles vivem na dependência do núcleo familiar. Isso gera sofrimento pra ele. Outros vêm com a esquizofrenia, mas ele não tem um local digno de moradia [...] (SUJEITO 1).
}

Além das questões já apresentadas, outra expressão da questão social ressaltada por algumas entrevistas é a violência, contra a mulher, contra o idoso, situações de cárcere privado, violência intrafamiliar, tanto com a pessoa com transtorno mental quanto com sua família.

Assim, as expressões da questão social citadas pelas entrevistadas são: preconceito, estigma, vulnerabilidade social, baixa renda ou pobreza - que envolve falta de moradia ou situações de moradia precária, falta de locomoção ou transporte, falta de alimentação, dentre outros -, baixa escolaridade, relações de emprego precário ou desemprego, violência de vários tipos, isolamento ou abandono familiar e até mesmo uso de álcool e outras drogas, apesar de o CAPS do tipo II não ser destinado a usuários desse tipo, tendo um tipo de serviço exclusivo para isso, o Centro de Atenção Psicossocial para pessoas com álcool e outras drogas (CAPSad). 
Conhecer as expressões da questão social presentes em determinado espaço de atuação de faz essencial para um trabalho qualificado, já que são elas que irão demandar ao assistente social uma resposta.

\section{Considerações finais}

Pode-se compreender que o Serviço Social tem na questão social e suas expressões o seu objeto de trabalho, pois são as demandas postas pelos seus usuários que impõe ao assistente social a necessidade de uma intervenção, visando, necessariamente, o fortalecimento dos direitos desses sujeitos. Assim, coloca-se aos assistentes sociais o grande desafio de atuar frente à questão social e suas expressões, buscando "projetar e forjar formas de resistência e de defesa da vida" (IAMAMOTO, 2008, p.27).

Na saúde mental, as expressões da questão social vão se colocar muito além da questão da "loucura", mas em tudo que permeia a vida desse sujeito com transtorno mental que trás consigo uma série de direitos violados, historicamente.

Foi possível concluir que o grande público-alvo dos CAPSs II de Teresina é de pessoas que, além de sofrerem de transtorno mental severo e persistente, sofrem também com a questão da pobreza, demandando, portanto, por uma atenção que vá além da assistência em saúde mental, transcorrendo as diversas expressões da questão social.

Compreender que os usuários dos CAPSs são, predominantemente, pessoas de uma classe social mais vulnerável implica, necessariamente, em compreender a realidade dos serviços de saúde pública no Brasil que, apesar de serem abertos a todos os públicos, o acesso maior se dá por sujeitos empobrecidos da população. Tal fato remete a visão imposta pelo ideário neoliberal, gerando uma dualidade discriminatória entre os que podem e os que não podem pagar pelos serviços levando também a uma diminuição da credibilidade dos serviços públicos, que ficam cada vez mais sucateados.

Nessa perspectiva, apesar de o Piauí constar com uma ampla gama de serviços públicos de saúde mental - considerado como o oitavo Estado brasileiro com melhor cobertura de CAPSs pelo Ministério da Saúde (BRASIL, 2012) - no entanto, faz-se necessário que tais serviços sejam vistos, tanto pela sociedade quanto pelo Estado, enquanto integrantes de uma política pública de responsabilidade estatal, que deve ser oferecida integral e universalmente a todos os cidadãos brasileiros, independente de classe social. Política pública essa que tendeu historicamente, no imaginário social, a ser percebida como um serviço para pobres e de qualidade ruim ou duvidosa, como a maioria dos serviços públicos é representado socialmente. 
E é justamente por isso que se torna essencial aos assistentes sociais - mas não só a eles - à defesa da saúde e, consequentemente, da saúde mental, como um direito social que necessita ser fortalecido.

\title{
THE EXPRESSIONS OF SOCIAL ISSUE IN MENTAL HEALTH: An analysis in 4 CAPS II of Teresina - PI
}

\begin{abstract}
This article aims to examine the social issue's expressions and its main demands placed for social service workers in their mental health job, using as scenarios the 4 Centros de Atenção Psicossocial (CAPSs) II, at Teresina - PI. It is a field survey, in which respondents were 8 social workers and analyzed his lines based on the dialectical method of Marx (1989), in a quest for ideal reproduction of the real movement. So, we tried to reconstruct the process object historically given, in addition to its phenomenal appearance, resulting from a theoretical elaboration, based on the literature on the subject, with an emphasis on Iamamoto (2001 ; 2008) , Rosa (2008) apart from the use of data and documents of the Ministry of Health (BRASIL, 2004; 2012). It was found that most users of these services are people who, besides suffering with mental disorder also suffer from poverty and its consequences, which will require the social worker attention that goes beyond mental health care, spending the various expressions of social issues.
\end{abstract}

Keywords: Social Service. Mental health. Social Issues.

\section{LAS EXPRESIONES DE CUESTIÓN SOCIAL EN SALUD MENTAL: Un análisis en 4 CAPS II de Teresina - PI}

\section{Resumen}

Este artículo tiene como objetivo examinar las expresiones de los cuestión social y las principales demandas puso trabajadores sociales en su trabajo en materia de salud mental, utilizando como escenarios 4 Centros de Atención Psicosocial (CAPS) II la ciudad de Teresina - PI. Se trata de un estudio de campo, en el que los encuestados eran 8 trabajadores sociales y se analizaron sus líneas de base en el método dialéctico de Marx (1989), en una búsqueda para la reproducción ideal del movimiento real. Así, tratamos de reconstruir el proceso objeto históricamente dada, además de su apariencia fenoménica, como resultado de una elaboración teórica, basada en la literatura sobre el tema, con énfasis en Iamamoto (2001; 2008), Rosa (2008) Además de la utilización de los datos y documentos de la Secretaría de Salud (BRASIL, 2004; 2012). Se encontró que la mayoría de los usuarios de estos servicios son personas que, además de sufrir de trastorno mental también sufren de la pobreza y sus consecuencias, lo que requerirá la atención del trabajador social que va más allá de la atención de salud mental, de pasar la diversas expresiones de las cuestiones sociales.

Palabras clave: Servicio Social. Salud Mental. Cuestión Social. 


\section{REFERÊNCIAS}

BRASIL. Ministério da Saúde. Saúde Mental em Dados v.11, Ano VII, n. 11. Informativo eletrônico. Brasília: outubro de 2012. Disponível em: <http://pt.scribd.com/doc/166268266/11-Saude-Mental-em-Dados-junho-de-2012pdf\#scribd> Acessado em: 27 jun. 2015.

Ministério da Saúde. Cadastro Nacional de Estabelecimento de Saúde (CNES). DATASUS. $<\mathrm{http}: / / \mathrm{cnes}$.datasus.gov.br/Mod_Ind_Unidade_Listar.asp?VTipo=70\&VListar $=1$ $\&$ VEstado=22\&VMun=\&VSubUni=\&VComp=> Acessado em: 27 jun. 2015.

Ministério da Saúde. Secretaria de Atendimento à Saúde. Departamento de ações programáticas estratégicas. Saúde mental no SUS: os Centros de Atenção Psicossocial. Brasília: Ministério da Saúde, 2004.

IAMAMOTO, Marilda V. O Serviço Social na contemporaneidade: trabalho e formação profissional. São Paulo: Cortez, 2008.

. A Questão Social no Capitalismo. In: Temporalis. Brasília: ABEPSS, n.3. 2001.

MACHADO, Graziela S. Tendências e dilemas do processo de trabalho no CAPS: percepções dos assistentes sociais. In: BISNETO, José A.; NICACIO, Erimaldo M. (Orgs). A prática do assistente social na saúde mental. Rio de Janeiro: Editora UFRJ, 2013, p. 139-166.

MARX, Karl. Contribuição para a crítica da economia política. Tradução de Maria Helena Barreiro Alves. São Paulo: Edições Mandacaru, 1989.

NETTO, José Paulo. Cinco notas a propósito da "questão social”. In: NETTO, José Paulo. Capitalismo monopolista e Serviço Social. São Paulo: Cortez, 8ed, 2011. p.151-162.

ROSA, Lúcia C. dos Santos; CAMPOS, Rosana T. Onocko. Saúde mental e classe social: CAPS, um serviço de classe e interclasses. In: Serviço Social e Sociedade. São Paulo, n.114, abr./jun., 2013, p.311-331.

ROSA, Lúcia C. dos S. Transtorno mental e o cuidado na família.2. ed. São Paulo: Cortez, 2008.

TRINDADE, Rosa L. Prédes. Ações profissionais, procedimentos e instrumentos no trabalho dos assistentes sociais nas políticas sociais. In: SANTOS, Cláudia M. dos; BACKX, Sheila; GUERRA, Yolanda (Org.). A dimensão técnico-operativa no Serviço Social: desafios contemporâneos. Juiz de fora: Ed. UFJF, 2012. p.69-102.

Data de recebimento: $27 / 06 / 15$

Data de aceite: $28 / 07 / 16$ 


\section{Sobre o autor:}

Sofia laurentino Barbosa Pereira é Doutoranda em Políticas Públicas (UFPI) e Assistente Social. Endereço eletrônico: sofia_lbp@ hotmail.com

Simone De Jesus Guimarães é Doutora em Serviço Social pela PUC-SP, professora do programa de pós graduação em políticas públicas e do departamento de Serviço Social da UFPI, assistente social. Endereço eletrônico: simone.guimaraes@uol.com.br 